Annals of Pure and Applied Mathematics

Vol. 15, No. 1, 2017, 105-114

ISSN: 2279-087X (P), 2279-0888(online)

Published on 11 December 2017

www.researchmathsci.org

DOI: http://dx.doi.org/10.22457/apam.v15n1a10

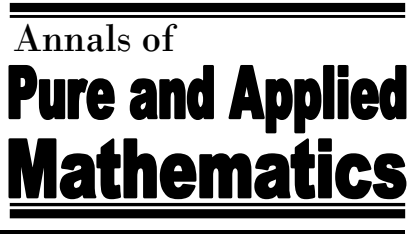

\title{
$k$-Super Harmonic Mean Labeling of Certain Snake Graphs
}

\author{
M. Tamilselvi ${ }^{1}$ and $N$. Revathi ${ }^{2}$ \\ ${ }^{1}$ Department of Mathematics, SeethalakshmiRamaswami College \\ Tiruchirappalli -620002, Tamilnadu, India. Email: madura.try@gmail.com \\ ${ }^{2}$ Department of Mathematics, SeethalakshmiRamaswami College \\ Tiruchirappalli-620002, Tamilnadu, India. Email: revathisignin@gmail.com \\ Received 2 November 2017; accepted 9 December 2017
}

Abstract. Harmonic mean labeling was introduced by Sandhya et al. We extend this notion to k-super harmonic mean labeling. In this paper, we investigate k-Super harmonic mean labeling of some snake graphs.

Keywords: Super harmonic mean labeling, Super harmonic mean graph, k-Super harmonic mean labeling, k-Super harmonic mean graph.

AMS Mathematics Subject Classification (2010): 05 C78

\section{Introduction}

By a graph $G=(V(G), E(G))$ with $p$ vertices and $q$ edges we mean a simple, connected and undirected graph. In this paper a brief summary of definitions and other information is given in order to maintain compactness. The term not defined here are used in the sense of Harary [3].

A graph labelingis an assignment of integers to the vertices or edges or both subject to certain conditions. A useful survey on graph labeling by Gallian (2016) can be found in [1]. Somasundaram and Ponraj [12] have introduced the notion of mean labeling of graphs. Ponraj and Ramya introduced Super mean labeling of graphs in [5]. Somasundaram and Sandhya introduced the concept of Harmonic mean labeling in [6] and studied their behavior in $[7,8,9]$. Sandhya and David Raj introduced Super harmonic labeling in [9]. k-super harmonic mean labeling was introduced by Tamilselvi and Revathi in [14]. In this paper, we investigate k-Super harmonic mean labeling of some snake related graphs.

\section{Preliminaries}

Definition 2.1. Let $\mathrm{G}$ be a (p, q) graph and $f: V(G) \rightarrow\{1,2,3 \ldots, p+q\}$ be an injection. For each edge e $=\mathrm{uv}_{\text {, let }} \mathrm{f}^{*}(\mathrm{e})=\left\lceil\frac{2 \mathrm{f}(\mathrm{u}) \mathrm{f}(\mathrm{v})}{\mathrm{f}(\mathrm{u})+\mathrm{f}(\mathrm{v})}\right\rceil$ or $\left\lfloor\frac{2 \mathrm{f}(\mathrm{u}) \mathrm{f}(\mathrm{v})}{\mathrm{f}(\mathrm{u})+\mathrm{f}(\mathrm{v})}\right\rceil$, then $\mathrm{f}$ is called Super harmonic mean labeling if $f(V) \cup\left\{\mathrm{f}^{*}(e): e \in E(G)\right\}=\{1,2, \ldots, p+q\}$. A graph that admits a Super harmonic mean labeling is called Super harmonic mean graph. 


\section{Tamilselvi and N. Revathi}

Definition 2.2. Let $\mathrm{G}$ be a (p, q) graph and $f: V(G) \rightarrow\{k, k+1, k+2, \ldots, p+q+k-$ $1\}$ be an injection. For each edge $e=u v$, let $f^{*}(e)=\left\lceil\frac{2 \mathrm{f}(\mathrm{u}) \mathrm{f}(\mathrm{v})}{\mathrm{f}(\mathrm{u})+\mathrm{f}(\mathrm{v})}\right\rceil$ or $\left\lfloor\frac{2 \mathrm{f}(\mathrm{u}) \mathrm{f}(\mathrm{v})}{\mathrm{f}(\mathrm{u})+\mathrm{f}(\mathrm{v})}\right\rceil$, then $\mathrm{f}$ is called $k$-Super harmonic mean labeling if $f(V) \cup\left\{\mathrm{f}^{*}(e): e \in E(G)\right\}=\{k, k+1, k+2, \ldots$ $, p+q+k-1\}$. A graph that admits a $k$-Super harmonic mean labeling is called $k$-Super harmonic mean graph.

Definition 2.3. A Triangular snake $T_{n}$ is obtained from a path $u_{1}, u_{2}, \ldots, u_{n}$ by joining $u_{i}$ and $u_{i+1}$ to a new vertex $v_{i}$ for $1 \leq i \leq n-1$.

Definition 2.4. An Alternate Triangular snake $A\left(T_{n}\right)$ is obtained from a path $u_{1}, u_{2}, \ldots, u_{n}$ by joining $u_{i}$ and $u_{i+1}$ alternatively to a new vertex $v_{i}$.

Definition 2.5. A Quadrilateral snake $Q_{n}$ is obtained from a path $u_{1}, u_{2}, \ldots, u_{n}$ by joining $u_{i}$ and $u_{i+1}$ to new vertices $v_{i}$ and $w_{i}$ for $1 \leq i \leq n-1$ respectively and then joining $v_{i}$ and $w_{i}$.

Definition 2.6. An Alternate Quadrilateral snakeA $\left(Q_{n}\right)$ is obtained from a path $u_{1}, u_{2}, \ldots, u_{n}$ by joining $u_{i}$ and $u_{i+1}$ alternatively to new vertices $v_{i}$ and $w_{i}$ respectively and then joining $v_{i}$ and $w_{i}$.

\section{Main results}

Theorem 3.1. A Triangular snake $T_{n}(n \geq 2)$ is $\mathrm{k}$ - super harmonic mean graph for all $k \geq 2$.

Proof: Let $V\left(T_{n}\right)=\left\{u_{i} ; 1 \leq i \leq n, v_{i} ; 1 \leq i \leq n-1\right\}$

$E\left(T_{n}\right)=\left\{u_{i} u_{i+1} ; 1 \leq i \leq n-1, u_{i} v_{i} ; 1 \leq i \leq n-1, u_{i+1} v_{i} ; 1 \leq i \leq n-1\right\}$

be denoted as in the following figure

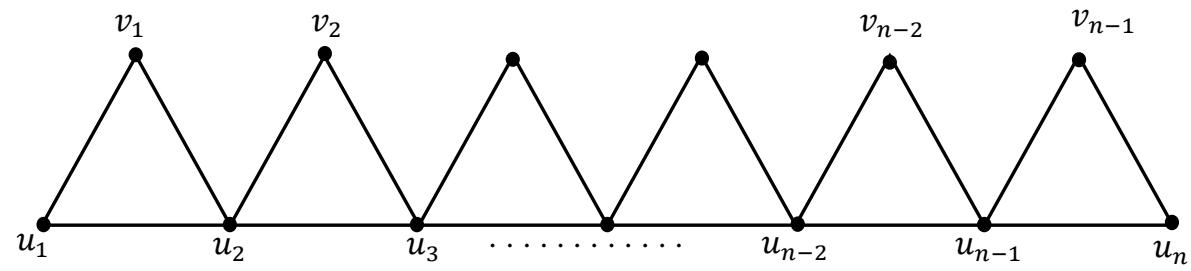

Figure 1:

First we label the vertices as follows

Define a function $f: V\left(T_{n}\right) \rightarrow\{k, k+1, k+2, \ldots k+p+q-1\}$ by

$$
\begin{aligned}
& f\left(u_{1}\right)=k+3 \\
& f\left(u_{i}\right)=k+5 i-5, \text { for } 2 \leq i \leq n \\
& f\left(v_{1}\right)=k \\
& f\left(v_{i}\right)=k+5 i-2, \text { for } 2 \leq i \leq n-1 .
\end{aligned}
$$

Then the induced edge labels are

$$
\begin{aligned}
& f^{*}\left(u_{1} u_{2}\right)=k+4 \\
& f^{*}\left(u_{i} u_{i+1}\right)=k+5 i-3, \text { for } 2 \leq i \leq n-1 \\
& f^{*}\left(u_{i} v_{i}\right)=k+5 i-4, \text { for } 1 \leq i \leq n-1
\end{aligned}
$$


k-Super Harmonic Mean Labeling Of Certain snake Graphs

$f^{*}\left(v_{1} u_{2}\right)=k+2$

$f^{*}\left(v_{i} u_{i+1}\right)=k+5 i-1$, for $2 \leq i \leq n-1$.

Thus $f(V) \cup\left\{f^{*}(e): e \in E(G)\right\}=\{k, k+1, k+2, \ldots, k+p+q-1\}$.

Hence $T_{n}$ is a $\mathrm{k}$-Super harmonic mean graph for all $k \geq 2$.

\section{Example 3.1.}

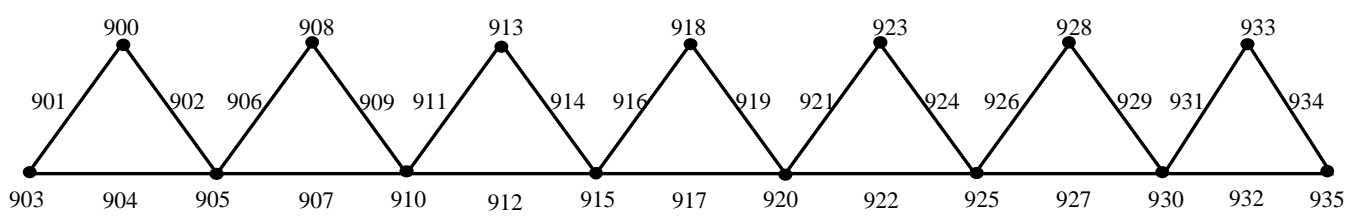

Figure 2: 900-Super harmonic mean labeling of $\mathrm{T}_{8}$

Theorem 3.2. An alternate Triangular snake $A\left(T_{n}\right)(n \geq 3)$ is $\mathrm{k}$ - super harmonic mean graph for all $k \geq 2$, if the triangle starts from the first vertex of $A\left(T_{n}\right)$.

Proof: Consider a path $u_{1}, u_{2}, \ldots, u_{n}$.

To construct alternate triangular snake join $u_{i}$ and $u_{i+1}$ alternatively with a new vertex $v_{i}$.

The ordinary labeling is

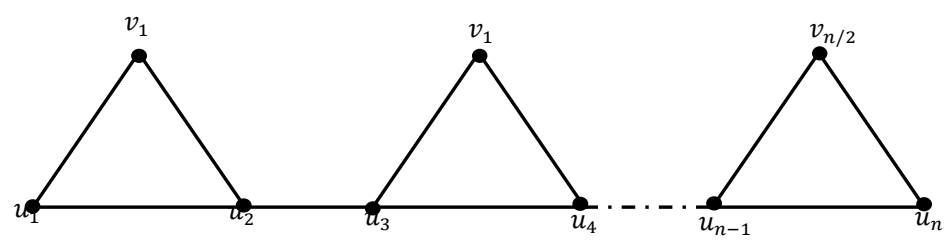

Figure 3:

Here we consider two cases

Case (i): If $\mathrm{n}$ is even

Define a function $f: V\left(A\left(T_{n}\right)\right) \rightarrow\{k, k+1, k+2, \ldots k+p+q-1\}$ by

$$
\begin{aligned}
& f\left(u_{1}\right)=k+3 \\
& f\left(u_{2 i-1}\right)=k+7(i-1), \text { for } 2 \leq i \leq n / 2 \\
& f\left(u_{2 i}\right)=k+7 i-2, \text { for } 1 \leq i \leq n / 2 \\
& f\left(v_{1}\right)=k \\
& f\left(v_{i}\right)=k+7 i-4, \text { for } 2 \leq i \leq n / 2 .
\end{aligned}
$$

Then the induced edge labels are

$$
\begin{aligned}
& f^{*}\left(u_{1} u_{2}\right)=k+4 \\
& f^{*}\left(u_{2 i} u_{2 i+1}\right)=k+7 i-1, \text { for } 1 \leq i \leq \frac{n}{2}-1 \\
& f^{*}\left(u_{2 i-1} u_{2 i}\right)=k+7 i-5, \text { for } 2 \leq i \leq n / 2 \\
& f^{*}\left(u_{2 i-1} v_{i}\right)=k+7 i-6, \text { for } 1 \leq i \leq n / 2 \\
& f^{*}\left(u_{2} v_{1}\right)=k+2 \\
& f^{*}\left(u_{2 i} v_{i}\right)=k+7 i-3, \text { for } 2 \leq i \leq n / 2 .
\end{aligned}
$$

Case (ii) : If $\mathrm{n}$ is odd

Define a function $f: V\left(A\left(T_{n}\right)\right) \rightarrow\{k, k+1, k+2, \ldots k+p+q-1\}$ by 


\section{Tamilselvi and N. Revathi}

$$
\begin{aligned}
& f\left(u_{1}\right)=k+3 \\
& f\left(u_{2 i-1}\right)=k+7(i-1), \text { for } 2 \leq i \leq \frac{n+1}{2} \\
& f\left(u_{2 i}\right)=k+7 i-2, \text { for } 1 \leq i \leq \frac{n-1}{2} \\
& f\left(v_{1}\right)=k \\
& f\left(v_{i}\right)=k+7 i-4, \text { for } 2 \leq i \leq \frac{n-1}{2} .
\end{aligned}
$$

Then the induced edge labels are

$$
\begin{aligned}
& f^{*}\left(u_{1} u_{2}\right)=k+4 \\
& f^{*}\left(u_{2 i} u_{2 i+1}\right)=k+7 i-1, \text { for } 1 \leq i \leq \frac{n-1}{2} \\
& f^{*}\left(u_{2 i-1} u_{2 i}\right)=k+7 i-5, \text { for } 2 \leq i \leq \frac{n-1}{2} \\
& f^{*}\left(u_{2 i-1} v_{i}\right)=k+7 i-6, \text { for } 1 \leq i \leq \frac{n-1}{2} \\
& f^{*}\left(u_{2} v_{1}\right)=k+2 \\
& f^{*}\left(u_{2 i} v_{i}\right)=k+7 i-3, \text { for } 2 \leq i \leq \frac{n-1}{2}
\end{aligned}
$$

Thus $f(V) \cup\left\{f^{*}(e): e \epsilon E(G)\right\}=\{k, k+1, k+2, \ldots, k+p+q-1\}$.

Hence $A\left(T_{n}\right)$, is a $\mathrm{k}$-Super harmonic mean graph for all $k \geq 2$, if the triangle starts from the first vertex of $A\left(T_{n}\right)$.

\section{Example 3.2.}

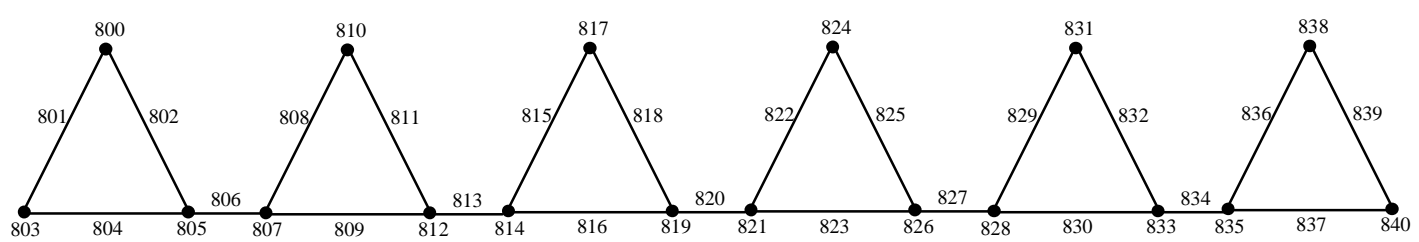

Figure 4: 800 - Super harmonic mean labeling of $A\left(T_{12}\right)$

Theorem 3.3. An Alternate Triangular snake $A\left(T_{n}\right)(n \geq 3)$ is $\mathrm{k}$ - super harmonic mean graph for all $k \geq 1$, if the triangle starts from the second vertex of $A\left(T_{n}\right)$.

Proof: The ordinary labeling is

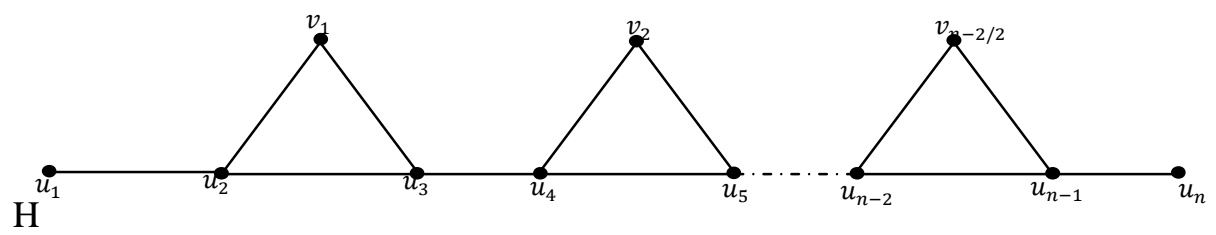

Figure 5:

Here we consider two cases

Case (i): If $\mathrm{n}$ is even

Define a function $f: V\left(A\left(T_{n}\right)\right) \rightarrow\{k, k+1, k+2, \ldots k+p+q-1\}$ by

$$
\begin{aligned}
& f\left(u_{2 i-1}\right)=k+7(i-1), \\
& f\left(u_{2 i}\right)=k+7 i-5, \quad \text { for } 1 \leq i \leq n / 2 \\
& \text { for } 1 \leq i \leq n / 2
\end{aligned}
$$


k-Super Harmonic Mean Labeling Of Certain snake Graphs

$$
f\left(v_{i}\right)=k+7 i-2, \quad \text { for } 1 \leq i \leq \frac{n-2}{2} .
$$

Then the induced edge labels are

$$
\begin{aligned}
& f^{*}\left(u_{2 i-1} u_{2 i}\right)=k+7 i-6, \text { for } 1 \leq i \leq n / 2 \\
& f^{*}\left(u_{2 i} u_{2 i+1}\right)=k+7 i-3, \text { for } 1 \leq i \leq \frac{n-2}{2} \\
& f^{*}\left(u_{2 i} v_{i}\right)=k+7 i-4, \text { for } 1 \leq i \leq \frac{n-2}{2} . \\
& f^{*}\left(u_{2 i+1} v_{i}\right)=k+7 i-1, \text { for } 1 \leq i \leq \frac{n-2}{2} .
\end{aligned}
$$

Case (ii) : If $\mathrm{n}$ is odd

Define a function $f: V\left(A\left(T_{n}\right)\right) \rightarrow\{k, k+1, k+2, \ldots k+p+q-1\}$ by

$$
\begin{aligned}
& f\left(u_{2 i-1}\right)=k+7(i-1), \text { for } 1 \leq i \leq \frac{n+1}{2} \\
& f\left(u_{2 i}\right)=k+7 i-5, \text { for } 1 \leq i \leq \frac{n-1}{2} \\
& f\left(v_{i}\right)=k+7 i-2, \text { for } 1 \leq i \leq \frac{n-1}{2} .
\end{aligned}
$$

Then the induced edge labels are

$$
\begin{aligned}
& f^{*}\left(u_{2 i-1} u_{2 i}\right)=k+7 i-6, \text { for } 1 \leq i \leq \frac{n-1}{2} \\
& f^{*}\left(u_{2 i} u_{2 i+1}\right)=k+7 i-3, \text { for } 1 \leq i \leq \frac{n-1}{2} \\
& f^{*}\left(u_{2 i} v_{i}\right)=k+7 i-4, \text { for } 1 \leq i \leq \frac{n-1}{2} \\
& f^{*}\left(u_{2 i+1} v_{i}\right)=k+7 i-1, \text { for } 1 \leq i \leq \frac{n-1}{2}
\end{aligned}
$$

Thus $f(V) \cup\left\{f^{*}(e): e \epsilon E(G)\right\}=\{k, k+1, k+2, \ldots, k+p+q-1\}$.

Hence $A\left(T_{n}\right)$ is a $\mathrm{k}$-Super harmonic mean graph for all $k \geq 1$, if the triangle starts from the second vertex of $A\left(T_{n}\right)$.

\section{Example 3.3.}

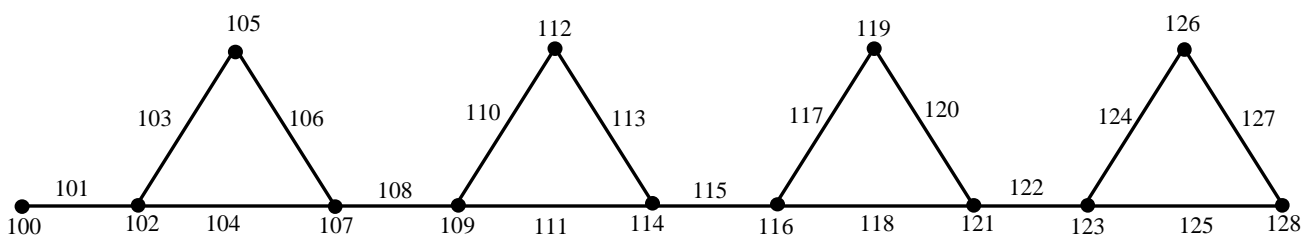

Figure 6: 100 - Super harmonic mean labeling of $A\left(T_{9}\right)$

Theorem 3.4. A Quadrilateral snake $Q_{n}(n \geq 2)$ is k - super harmonic mean graph for all $k \geq 2$.

Proof: Let $V\left(Q_{n}\right)=\left\{u_{i} ; 1 \leq i \leq n, v_{i}, w_{i}, ; \leq i \leq n-1\right\}$

$$
E\left(Q_{n}\right)=\left\{u_{i} u_{i+1}, u_{i} v_{i}, v_{i} w_{i}, w_{i} u_{i+1} ; 1 \leq i \leq n-1\right\}
$$

be denoted as in the following figure

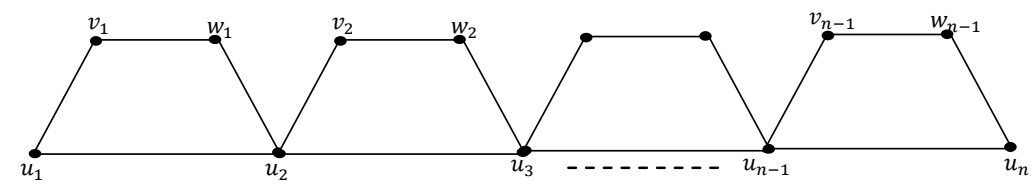

Figure7: 


\section{Tamilselvi and N. Revathi}

First we label the vertices as follows

Define a function $f: V\left(Q_{n}\right) \rightarrow\{k, k+1, k+2, \ldots k+p+q-1\}$ by

$$
\begin{aligned}
& f\left(u_{1}\right)=\left\{\begin{array}{l}
k+5 \text { if } k=2 \\
k+4 \text { if } k \geq 3
\end{array}\right. \\
& f\left(u_{i}\right)=k+7 i-7, \text { for } 2 \leq i \leq n \\
& f\left(v_{1}\right)=k \\
& f\left(v_{i}\right)=k+7 i-5, \text { for } 2 \leq i \leq n-1 \\
& f\left(w_{1}\right)=k+3 \\
& f\left(w_{i}\right)=k+7 i-2, \text { for } 2 \leq i \leq n-1 .
\end{aligned}
$$

Then the induced edge labels are

$$
\begin{aligned}
& f^{*}\left(u_{1} u_{2}\right)=k+6 \\
& f^{*}\left(u_{i} u_{i+1}\right)=k+7 i-4, \text { for } 2 \leq i \leq n-1 \\
& f^{*}\left(u_{1} v_{1}\right)=k+2 \\
& f^{*}\left(u_{i} v_{i}\right)=k+7 i-6, \text { for } 2 \leq i \leq n-1 \\
& f^{*}\left(w_{1} u_{2}\right)=\left\{\begin{array}{l}
k+4 \text { if } k=2 \\
k+5 \text { if } k \geq 3
\end{array}\right. \\
& f^{*}\left(w_{i} u_{i+1}\right)=k+7 i-1, \text { for } 2 \leq i \leq n-1 \\
& f^{*}\left(v_{1} w_{1}\right)=k+1 \\
& f^{*}\left(v_{i} w_{i}\right)=k+7 i-3, \text { for } 2 \leq i \leq n-1 .
\end{aligned}
$$

Thus $f(V) \cup\left\{f^{*}(e): e \in E(G)\right\}=\{k, k+1, k+2, \ldots, k+p+q-1\}$.

Hence $Q_{n}$ is a $\mathrm{k}$-Super harmonic mean graph for all $k \geq 2$.

\section{Example 3.4.}

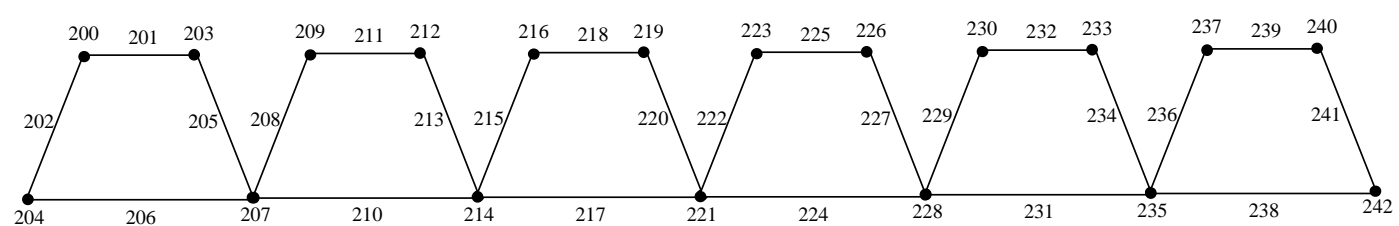

Figure 8: 200 - super harmonic mean labeling of $Q_{7}$

Theorem 3.5. An alternate Quadrilateral $\operatorname{snake} A\left(Q_{n}\right)(n \geq 3)$ is $\mathrm{k}$ - super harmonic mean graph for all $k \geq 2$, if the quadrilateral starts from the first vertex of $A\left(Q_{n}\right)$.

Proof: Consider a path $u_{1}, u_{2}, \ldots, u_{n}$.

To construct alternate quadrilateral snake join $u_{i}$ and $u_{i+1}$ alternatively to new vertices $v_{i}, w_{i}$ respectively and then joining $v_{i}$ and $w_{i}$

The ordinary labeling is

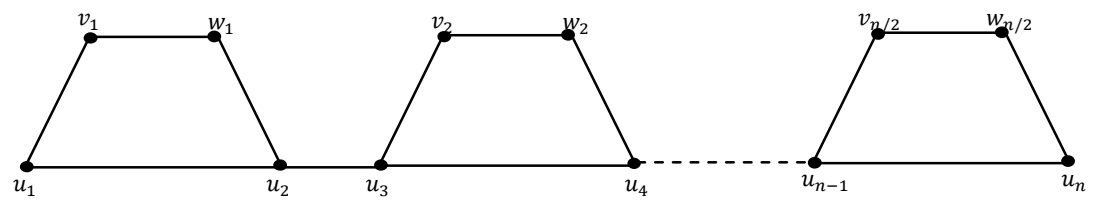

Figure 9: 
k-Super Harmonic Mean Labeling Of Certain snake Graphs

Here we consider two cases

Case (i): If $\mathrm{n}$ is even

Define a function $f: V\left(A\left(Q_{n}\right)\right) \rightarrow\{k, k+1, k+2, \ldots k+p+q-1\}$ by

$$
\begin{aligned}
& f\left(u_{1}\right)=\left\{\begin{array}{l}
k+5 \text { if } k=2 \\
k+4 \text { if } k \geq 3
\end{array}\right. \\
& f\left(u_{2 i}\right)=k+9 i-2, \text { for } 1 \leq i \leq n / 2 \\
& f\left(u_{2 i-1}\right)=k+9 i-9, \text { for } 2 \leq i \leq n / 2 \\
& f\left(v_{1}\right)=k \\
& f\left(v_{i}\right)=k+9 i-7, \text { for } 2 \leq i \leq n / 2 \\
& f\left(w_{1}\right)=k+3 \\
& f\left(w_{i}\right)=k+9 i-4, \text { for } 2 \leq i \leq n / 2 .
\end{aligned}
$$

Then the induced edge labels are

$$
\begin{aligned}
& f^{*}\left(u_{1} u_{2}\right)=k+6 \\
& f^{*}\left(u_{2 i} u_{2 i+1}\right)=k+9 i-1, \text { for } 1 \leq i \leq \frac{n}{2}-1 \\
& f^{*}\left(u_{2 i-1} u_{2 i}\right)=k+9 i-6, \text { for } 2 \leq i \leq \frac{n}{2} \\
& f^{*}\left(u_{1} v_{1}\right)=k+2 \\
& f^{*}\left(u_{2 i-1} v_{i}\right)=k+9 i-6, \text { for } 2 \leq i \leq n / 2 \\
& f^{*}\left(w_{1} u_{2}\right)=\left\{\begin{array}{l}
k+4 \text { if } k=2 \\
k+5 \text { if } k \geq 3
\end{array}\right. \\
& f^{*}\left(w_{i} u_{2 i}\right)=k+9 i-3, \text { for } 2 \leq i \leq n / 2 \\
& f^{*}\left(v_{1} w_{1}\right)=k+1 \\
& f^{*}\left(v_{i} w_{i}\right)=k+9 i-5, \text { for } 2 \leq i \leq n-1 \text {. }
\end{aligned}
$$

\section{Case (ii) : If $\mathrm{n}$ is odd}

$$
\begin{aligned}
& f\left(u_{1}\right)=\left\{\begin{array}{l}
k+5 \text { if } k=2 \\
k+4 \text { if } k \geq 3
\end{array}\right. \\
& f\left(u_{2 i}\right)=k+9 i-2, \text { for } 1 \leq i \leq \frac{n-1}{2} \\
& f\left(u_{2 i-1}\right)=k+9 i-9, \text { for } 2 \leq i \leq \frac{n+1}{2} \\
& f\left(v_{1}\right)=k \\
& f\left(v_{i}\right)=k+9 i-7, \text { for } 2 \leq i \leq \frac{n-1}{2} \\
& f\left(w_{1}\right)=k+3 \\
& f\left(w_{i}\right)=k+9 i-4, \text { for } 2 \leq i \leq \frac{n-1}{2}
\end{aligned}
$$

Then the induced edge labels are

$$
\begin{aligned}
& f^{*}\left(u_{1} u_{2}\right)=k+6 \\
& f^{*}\left(u_{2 i} u_{2 i+1}\right)=k+9 i-1, \text { for } 1 \leq i \leq \frac{n-1}{2} \\
& f^{*}\left(u_{2 i-1} u_{2 i}\right)=k+9 i-6, \text { for } 2 \leq i \leq \frac{n-1}{2} \\
& f^{*}\left(u_{1} v_{1}\right)=k+2 \\
& f^{*}\left(u_{2 i-1} v_{i}\right)=k+9 i-8, \text { for } 2 \leq i \leq \frac{n-1}{2} \\
& f^{*}\left(w_{1} u_{2}\right)=\left\{\begin{array}{l}
k+4 \text { if } k=2 \\
k+5 \text { if } k \geq 3
\end{array}\right. \\
& f^{*}\left(w_{i} u_{2 i}\right)=k+9 i-3, \text { for } 2 \leq i \leq \frac{n-1}{2} \\
& f^{*}\left(v_{1} w_{1}\right)=k+1
\end{aligned}
$$




\section{Tamilselvi and N. Revathi}

$$
f^{*}\left(v_{i} w_{i}\right)=k+9 i-5, \text { for } 2 \leq i \leq \frac{n-1}{2} \text {. }
$$

Thus $f(V) \cup\left\{f^{*}(e): e \epsilon E(G)\right\}=\{k, k+1, k+2, \ldots, k+p+q-1\}$.

Hence $\mathrm{A}\left(Q_{n}\right)$ is a $\mathrm{k}$-Super harmonic mean graph for all $k \geq 2$, if the quadrilateral starts from the first vertex of $A\left(Q_{n}\right)$

\section{Example 3.5.}

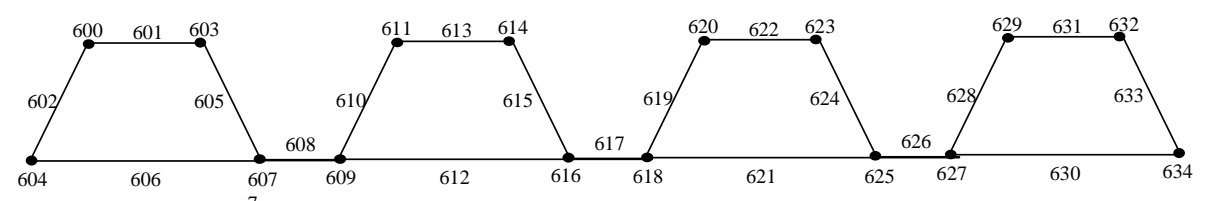

Figure 10: 600-Super harmonic mean labeling of $\mathrm{A}\left(\mathrm{Q}_{8}\right)$

Theorem 3.6. An alternate Quadrilateral snake $A\left(Q_{n}\right)(n \geq 3)$ is $\mathrm{k}$ - super harmonic mean graph for all $k \geq 2$, if the quadrilateral starts from the second vertex of $A\left(Q_{n}\right)$. Proof: The ordinary labeling is

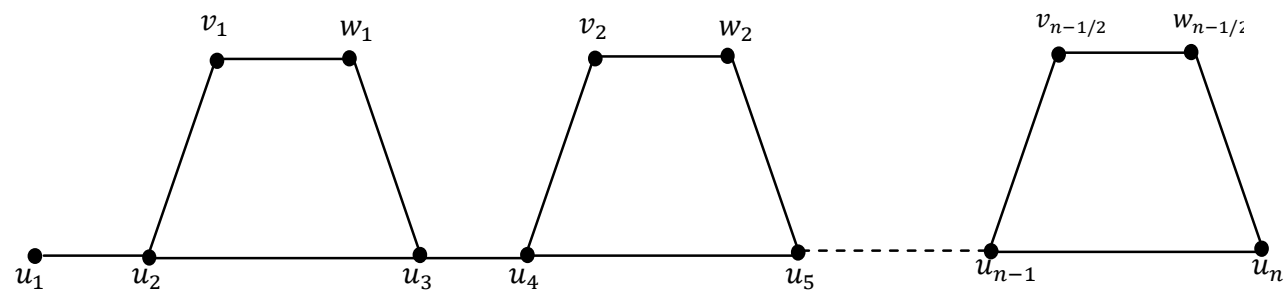

Figure 11:

Here we consider two cases

Case (i): If $\mathrm{n}$ is even

Define a function $\left.f: V\left(A Q_{n}\right)\right) \rightarrow\{k, k+1, k+2, \ldots k+p+q-1\}$ by

$$
\begin{aligned}
& f\left(u_{2 i}\right)=k+9 i-7 \text {, for } 1 \leq i \leq n / 2 \\
& f\left(u_{2 i-1}\right)=k+9 i-9, \text { for } 1 \leq i \leq n / 2 \\
& f\left(v_{1}\right)=\left\{\begin{array}{l}
k+5 \text { if } k=2 \\
k+4 \text { if } k \geq 3
\end{array}\right. \\
& f\left(v_{i}\right)=k+9 i-5, \text { for } 2 \leq i \leq \frac{n}{2}-1 \\
& f\left(w_{i}\right)=k+9 i-2, \text { for } 1 \leq i \leq \frac{n}{2}-1 \text {. }
\end{aligned}
$$

Then the induced edge labels are

$$
\begin{aligned}
& f^{*}\left(u_{2} u_{3}\right)=\left\{\begin{array}{l}
k+4 \text { if } k=2 \\
k+5 \text { if } k \geq 3
\end{array}\right. \\
& f^{*}\left(u_{2 i} u_{2 i+1}\right)=k+9 i-4, \text { for } 2 \leq i \leq \frac{n}{2}-1 \\
& f^{*}\left(u_{2 i-1} u_{2 i}\right)=k+9 i-8, \text { for } 1 \leq i \leq \frac{n}{2} \\
& f^{*}\left(u_{2 i} v_{i}\right)=k+9 i-6, \text { for } 1 \leq i \leq \frac{n}{2}-1
\end{aligned}
$$


k-Super Harmonic Mean Labeling Of Certain snake Graphs

$$
\begin{aligned}
& f^{*}\left(v_{i} w_{i}\right)=k+9 i-3, \text { for } 1 \leq i \leq \frac{n}{2}-1 \\
& f^{*}\left(w_{i} u_{2 i+1}\right)=k+9 i-1, \text { for } 1 \leq i \leq \frac{n}{2}-1
\end{aligned}
$$

Case (ii) : If $\mathrm{n}$ is odd

Define a function $\left.f: V\left(A Q_{n}\right)\right) \rightarrow\{k, k+1, k+2, \ldots k+p+q-1\}$ by

$$
\begin{aligned}
& f\left(u_{2 i}\right)=k+9 i-7, \text { for } 1 \leq i \leq \frac{n-1}{2} \\
& f\left(u_{2 i-1}\right)=k+9 i-9, \text { for } 1 \leq i \leq \frac{n+1}{2} \\
& f\left(v_{1}\right)=\left\{\begin{array}{l}
k+5 \text { if } k=2 \\
k+4 \text { if } k \geq 3
\end{array}\right. \\
& f\left(v_{i}\right)=k+9 i-5, \text { for } 2 \leq i \leq \frac{n-1}{2} \\
& f\left(w_{i}\right)=k+9 i-2, \text { for } 1 \leq i \leq \frac{n-1}{2} .
\end{aligned}
$$

Then the induced edge labels are

$$
\begin{aligned}
& f^{*}\left(u_{2} u_{3}\right)=\left\{\begin{array}{l}
k+4 \text { if } k=2 \\
k+5 \text { if } k \geq 3
\end{array}\right. \\
& f^{*}\left(u_{2 i} u_{2 i+1}\right)=k+9 i-4, \text { for } 2 \leq i \leq \frac{n-1}{2} \\
& f^{*}\left(u_{2 i-1} u_{2 i}\right)=k+9 i-8, \text { for } 1 \leq i \leq \frac{n-1}{2} \\
& f^{*}\left(u_{2 i} v_{i}\right)=k+9 i-6, \text { for } 1 \leq i \leq \frac{n-1}{2} \\
& f^{*}\left(v_{i} w_{i}\right)=k+9 i-3, \text { for } 1 \leq i \leq \frac{n-1}{2} . \\
& f^{*}\left(w_{i} u_{2 i+1}\right)=k+9 i-1, \text { for } 1 \leq i \leq \frac{n-1}{2}
\end{aligned}
$$

Thus $f(V) \cup\left\{f^{*}(e): e \in E(G)\right\}=\{k, k+1, k+2, \ldots, k+p+q-1\}$.

Hence $\mathrm{A}\left(Q_{n}\right)$ is a $\mathrm{k}$-Super harmonic mean graph for all $k \geq 2$, if the quadrilateral starts from the second vertex of $A\left(Q_{n}\right)$

\section{Example 3.6.}

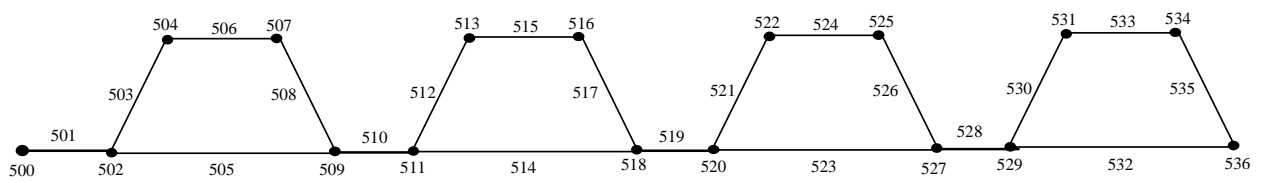

Figure 12: 500-Super harmonic mean labeling of $A\left(Q_{9}\right)$

\section{REFERENCES}

1. J.A.Gallian, A dynamic survey of graph labeling, The Electronic Journal of Combinatorics, DS6 2012.

2. B.Gayathri and M.Tamilselvi, k-super mean labeling of some trees and cycle related Graphs, Bulletin of Pure and Applied Sciences, 26E(2) (2007) 303-311.

3. F.Harary, Graph theory, Narosa Publishing House Reading, New Delhi (1998).

4. P.Jeyanthi and D.Ramya, Super mean labeling of some classes of graphs, International Journal of Math. Combin., 1 (2012) 83-91.

5. D.Ramya, R.Ponraj and P.Jeyanthi, Super mean labeling of graphs, Ars Combinatoria, 112 (2013) 65-72. 


\section{Tamilselvi and N. Revathi}

6. S.S.Sandhya, S.Somasundaram and R.Ponraj, Some results on Harmonic mean graphs, International Journal of Contemporary Mathematical Sciences, 7(4) (2012) 197-208.

7. S.S.Sandhya, S.Somasundaram and R. Ponraj, Some more results on Harmonic mean graphs, Journal of Mathematics Research, 4(1) (2012) 21 - 29.

8. S.S.Sandhya, S.Somasundaram and R.Ponraj, Harmonic mean labeling of some cycle related graphs, International Journal of Mathematical Analysis, 6(40) (2012) 19972005.

9. S.Sandhya and C.David Raj, Some results on super harmonic mean graphs, International Journal of Mathematics Trends and Technology, 6(2014).

10. S.S.Sandhya, E.E.R.Merly and B.Shiny, Some more results on super geometric mean labeling, International Journal of Mathematical Archive, 6(1) (2015) 121-132.

11. S.Avadayappan and R.Vasuki, New families of mean graphs, International J.Math. Combin, 2 (2010) 68-80.

12. S.Somasundaram and R.Ponraj, Mean labeling of graphs, National Academy of Science Letters, 26 (2003) $210-213$.

13. M.Tamilselvi, A study in graph theory- generalization of super mean labeling, Ph.D. Thesis, Vinayaka Mission University, Salem 2011.

14. M.Tamilselvi and N.Revathi, k-super harmonic mean labeling of some graphs, Arabhatta Journal of Mathematics and Informatics, 9(1) (2017) 779-787.

15. M.Tamilselvi and N.Revathi, k-super harmonic mean labeling of some disconnected graphs, International Journal of Recent Innovation in Engineering and Technology, 2(8) (2011). 